\title{
The regional medical campus model and rural family medicine practice in British Columbia: a retrospective longitudinal cohort study
}

\author{
Chris Y. Lovato PhD, Helen C.H. Hsu MSc, Joanna Bates MDCM, Oscar Casiro MD, Angela Towle PhD, \\ David Snadden MClSc MD
}

\section{Abstract}

Background: Regional medical campuses have been implemented across North America to address gaps in the physician workforce. We report findings from a study that examined the association between a combined model of regional medical campuses and students' decision to enter rural family medicine practice.

Methods: In 2004, the University of British Columbia added 2 regional medical campuses, 1 in a large population centre in a rural and coastal context and 1 in a medium-sized population centre in an isolated northern and rural context. Data were extracted from the University of British Columbia's Medical Education Database. Multivariable logistic regression examined the relationship of age, sex, rural background and campus location to students' choice of rural family medicine practice.

Results: There was an association between campus location and choice of family medicine versus other specialties. A rural background (odds ratio [OR] 2.59, 95\% confidence interval $[\mathrm{Cl}]$ 1.08-6.21) and training at either of the 2 regional medical campuses (OR $3.24,95 \% \mathrm{Cl} 1.19-8.83$ and OR $5.38,95 \% \mathrm{Cl} 2.24-12.91)$ predicted rural family practice.

Interpretation: Choosing to practise family medicine in a rural location was associated with having a rural background and having trained at a regional medical campus. These early results suggest that a combined regional campus model in medical education contributes to the rural family practice workforce.

\begin{abstract}
T n Canada, as in many other countries, access to a family physician remains problematic for many patients, especially those in northern, rural and remote communities. $^{1-4}$ In 2016, there were 234 physicians per 100000 population in Canada; $92 \%$ were located in urban areas and only $8 \%$ were located in rural areas, ${ }^{5}$ yet $18 \%$ of Canadians live in rural areas. ${ }^{6}$ Regional medical campuses represent an educational strategy for addressing health care workforce needs. ${ }^{7}$ Traditionally, regional medical campuses provide training in basic science, clinical training or both.

Physician maldistribution is evident in British Columbia, where physicians cluster mainly in urban areas. ${ }^{8}$ In 2004, the University of British Columbia (UBC) established a combined regional medical campus model $^{9}$ where, in addition to the main campus, 2 regional medical campuses provided both basic science and clinical training. Since then, many other medical schools in Canada and the United States have developed regional campuses. ${ }^{10}$ Students from rural backgrounds are more likely to practise in rural areas, ${ }^{11}$ and previous studies suggest that undergraduate rural training (especially longitudinal rural training) increases the likelihood of rural
\end{abstract}

practice. Research regarding undergraduate rural education models is sparse ${ }^{12}$ beyond descriptive studies, and evidence is lacking that these educational interventions increase the rural workforce. ${ }^{13}$ The primary objective of this study was to determine the association between a combined regional medical campus model and rural family medicine practice.

\section{Methods}

\section{Setting}

Community action in BC led to a collaboration between the UBC Faculty of Medicine (the only medical school in the province), the $\mathrm{BC}$ government, the University of Northern

\section{Competing interests: None declared.}

This article has been peer reviewed.

Correspondence to: David Snadden, david.snadden@ubc.ca CMAJ Open 2019. DOI:10.9778/cmajo.20180205 
British Columbia (UNBC) and the University of Victoria (UVic) to double the number of undergraduate medical school and residency seats by creating regional campuses. ${ }^{9}$

In the UBC combined model, regional medical campus students are allocated to their campus at the time of admission, spend the first semester at the main campus and then move to their regional campus for the remainder of their undergraduate education. All trainees remain students of UBC and the curriculum and assessment are the same across all campuses. The school is accredited as a single medical school and the undergraduate curriculum is governed with campus representation on all key committees. Teaching is shared across campuses, with lectures and laboratories delivered through videoconferencing, while small group sessions and clinical training are delivered locally. All students, regardless of training site, are required to complete clinical rotations across the same disciplines. Although the learning objectives, assessments and student performance are comparable across all campuses, there are important differences in the training context.

The main campus is located at UBC in Vancouver, whose metropolitan area population of 2.4 million is the largest in the province. ${ }^{14}$ Vancouver is culturally and ethnically diverse. There are 3 tertiary care teaching hospitals in the centre of the city and several university-affiliated large suburban hospitals. It is the site of specialized training for the province.

The Island Medical Program regional medical campus (IMP-RMC) is housed at UVic in the city of Victoria, Vancouver Island. The island is $32134 \mathrm{~km}^{2}$ in area and approximately half of the island's population (367 770) live in Victoria, a large population centre. ${ }^{14}$ The remaining population live in small and rural communities scattered across Vancouver Island and on neighbouring islands. There are 11 hospitals on Vancouver Island. By virtue of its context, students at the IMP-RMC are exposed to both urban and rural practitioners and have the opportunity to experience clinical practice in a range of small communities.

The Northern Medical Program regional medical campus (NMP-RMC) is housed at UNBC in Prince George, a northern and isolated medium-sized population centre of $86662^{14}$ servicing a vast and scattered geography with many rural communities. The economy has historically been reliant on natural resources. There is 1 hospital that is staffed by a range of general specialist physicians and full-service family physicians. The NMP-RMC has a particular mandate to encourage students to consider rural medical careers and it uses, as part of its admission process, a remote and rural suitability tool to identify applicants with rural backgrounds and affinity. ${ }^{15}$

\section{Design and sources of data}

This was a retrospective longitudinal cohort study. We extracted data from UBC's Medical Education Database, which links information about students from admissions through undergraduate and postgraduate training and into practice. The database includes linked data from the UBC admissions office, the undergraduate and postgraduate deans' offices and the Canadian Post-MD Education Registry as well as practice data from the Canadian Medical Directory, the Royal College of Physicians and Surgeons of Canada, the College of Family Physicians of Canada and provincial licensing bodies (e.g., the College of Physicians and Surgeons of BC and the College of Physicians and Surgeons of Ontario).

The cohort comprised all students admitted in the first 4 years after the regional medical campuses opened in 2004 (2004-2007). The 10-year time span for this study reflects the time required for a student entering medicine to complete undergraduate and postgraduate training in family medicine (at minimum $6 \mathrm{yr}$ ) and settle into independent practice (up to $4 \mathrm{yr}$ ). The final sample included trainees who were licensed to practise family medicine in Canada as of 2014 and excluded trainees who were practising in specialties other than family medicine, who were still in residency training or who were practising outside of Canada.

\section{Primary outcomes}

Practice location (rural family practice) was the primary outcome of interest. It was classified as urban or rural on the basis of the address listed in the Canadian Medical Directory (provided by trainees practising family medicine). To create the rural/urban variable we used postal code to classify location of practice using the 8-point Statistics Canada Statistical Area Classification. ${ }^{16}$ In our analysis, $1-3$ represent urban areas (census metropolitan or agglomeration areas with populations $\geq 10000$ ) and 4-8 represent rural areas (census subdivisions with populations < 10 000). These 2 categories reflect Statistics Canada's rural and small town (RST) definition. ${ }^{17}$

\section{Independent variables}

Using data from students who began their medical education training between 2004 and 2007, we constructed a campus variable with 3 categories representing training location (main campus, IMP-RMC, NMP-RMC). Sex, age at time of entry and rural background (based on RST definition using postal code of high school location) were also included as explanatory variables. The explanatory variables were chosen on the basis of previous studies identifying them as predictors of rural family practice. ${ }^{18,19}$

\section{Statistical analysis}

Analyses were conducted using SPSS software, version 23. We used $\chi^{2}$ analyses and Student $t$ test to evaluate associations between each explanatory variable and family practice location. We used multivariable logistic regression to examine the association of training at each campus location (main campus, IMP-RMC, NMP-RMC) with rural family practice. Wald statistics was used to determine which explanatory variables were significant in the model. We also used $\chi^{2}$ analyses to examine the association between campus location and trainees' residency choice (family medicine versus other specialties).

\section{Ethics approval}

This study (H15-02916-A001) was approved by the University of British Columbia Behavioural Research Ethics Board. 


\section{Results}

A total of 904 students entered their first year of medical school at UBC between 2004 and 2007. Of that total, 699 $(77.3 \%)$ completed their studies at the main campus, 104 $(11.5 \%)$ studied at the IMP-RMC and $101(11.2 \%)$ studied at the NMP-RMC. The average age of trainees at time of entry was 25 years (range 19-43 yr). The proportion of women $(56.2 \%)$ was slightly higher than that of men $(43.8 \%)$, and $8.9 \%$ of trainees had attended high school in a rural town (Table 1).

By 2015, 98.2\% (888/904) of trainees in the eligible sample had entered postgraduate medical training; $36.0 \%$ (320/888) of these trainees had chosen family medicine (221 from the main campus, 54 from the NMP-RMC and 45 from the IMP$\mathrm{RMC})$. The $\chi^{2}$ analysis revealed an association between campus location and specialty choice (family medicine v. other specialties; $\left.\chi^{2}[2,888]=22.89, p<0.05\right)($ Table 1$)$.

Over half (520/904; $57.5 \%)$ of trainees had completed licensing requirements and were practising in Canada (387 from the main campus, 71 from the NMP-RMC and 62 from the IMP$\mathrm{RMC}$ ). Of these, 309 were practising in family medicine (211 from the main campus, 56 from the NMP-RMC and 42 from the IMP-RMC). Excluded from the final sample were the over one-third $(352 / 904 ; 38.9 \%)$ of trainees who were still in postgraduate medical training, 1.8\% (16/904) of trainees who were practising outside of Canada and 1.8\% (16/904) trainees who were lost to follow-up or were not in practice (Figure 1).

\section{Rural family medicine}

Table 2 shows descriptive statistics for explanatory variables and their comparisons between rural and urban practice. Age, rural background and campus were significant variables on the basis of univariate analyses.

Findings from multivariable logistic regression on rural family practice (Table 3 ) indicate that students who trained at the IMP-RMC (odds ratio [OR] 3.24, 95\% confidence interval [CI] 1.19-8.83) or the NMP-RMC (OR 5.38, 95\% CI 2.24-12.91) were more likely to practise rural family medicine than students trained at the main campus after other variables were controlled for. Having a rural background (OR 2.59, 95\% CI 1.08-6.21) also predicted rural practice. Sex and age were not found to be associated with rural practice.

\section{Interpretation}

Choosing to practise family medicine in a rural location was associated with 2 factors: rural background and being trained at either of the regional medical campuses (i.e., IMP-RMC or NMP-RMC). This suggests that training context is a predictor of career choice and supports previous studies regarding the significance of a rural background. ${ }^{20} \mathrm{We}$ also found that a larger proportion of trainees from the regional medical campuses than from the main campus chose family medicine as their specialty.

Interestingly, NMP-RMC trainees were 5 times more likely than main campus trainees to practise rural family medicine, while IMP-RMC trainees were 3 times more likely to practise rural family medicine than trainees from the main campus. This may be due to the more intense exposure to rural practice that NMP-RMC trainees receive and the rural admissions process specific to the NMP-RMC. The NMP$\mathrm{RMC}$ used an admissions process involving identification of applicants with rural backgrounds and affinity. ${ }^{15}$ Taken

Table 1: Study sample at each stage of training by campus location

\begin{tabular}{|c|c|c|c|c|}
\hline Characteristic & Total & Main campus & IMP-RMC & NMP-RMC \\
\hline Entry into UBC MD training, no. & 904 & 699 & 104 & 101 \\
\hline Sex, female, no. $(\%)^{*}$ & $508(56.2)$ & $383(54.8)$ & $61(58.7)$ & $64(63.4)$ \\
\hline Age, yr, mean \pm SD & $25 \pm 5.2$ & $24 \pm 3.3$ & $25 \pm 3.6$ & $27 \pm 5.2$ \\
\hline Rural background, no. $(\%)^{*} \dagger$ & $77(8.9)$ & $40(6.0)$ & $11(11.0)$ & $26(26.8)$ \\
\hline Residency training, no. $\neq$ & 888 & 689 & 100 & 99 \\
\hline Family medicine, no. (\%)§ & $320(36.0)$ & $221(32.1)$ & $45(45.0)$ & $54(54.5)$ \\
\hline $\begin{array}{l}\text { Specialties other than family medicine, } \\
\text { no. }(\%) \S\end{array}$ & $568(64.0)$ & $468(67.9)$ & $55(55.0)$ & $45(45.5)$ \\
\hline Practising family medicine, no. & 309 & 211 & 42 & 56 \\
\hline Rural practice, no. (\%)ף & $40(13.0)$ & $14(6.6)$ & $7(16.7)$ & $19(33.9)$ \\
\hline Urban practice, no. (\%)ף & $269(87.0)$ & $197(93.4)$ & $35(83.3)$ & $37(66.1)$ \\
\hline \multicolumn{5}{|c|}{ 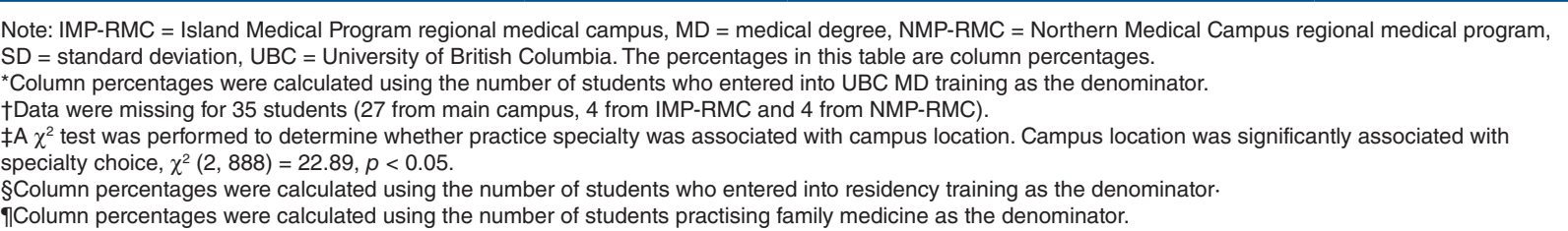 } \\
\hline
\end{tabular}




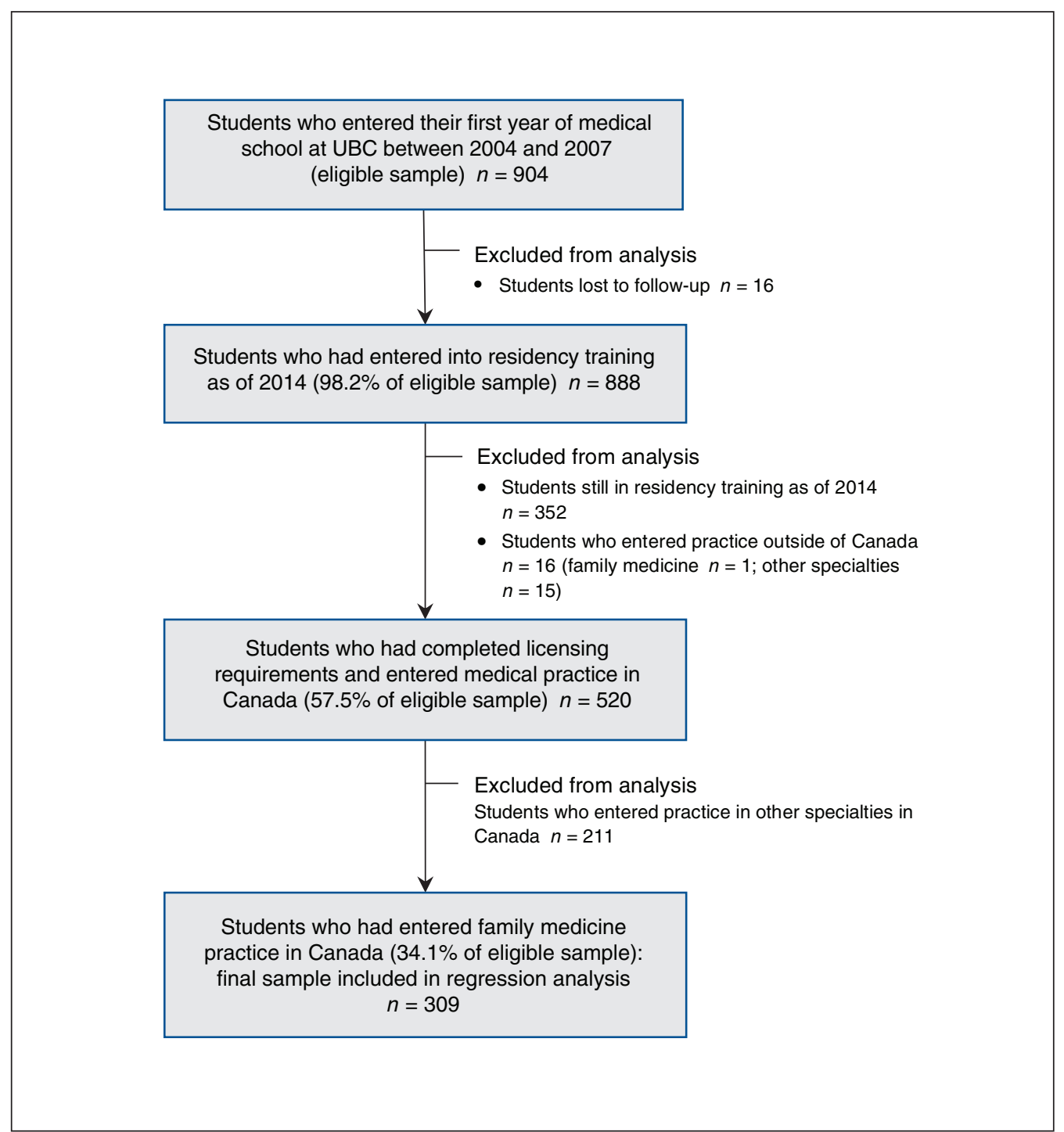

Figure 1: Flowchart of study sample at each stage of training.

together, these findings build on evidence that a rural campus with an approach that simultaneously addresses multiple factors can contribute to increasing the supply of rural physicians. ${ }^{21,22}$ Our results also support previous evidence that medical education in a rural location increases the number of medical graduates choosing rural practice. ${ }^{23-26}$

The association between practice and regional campus locations suggests that training context is related to career choice. A context such as Prince George, where there is 1 hospital with full-service family physicians caring for inpatients and where students encounter many family physicians, may have a significant influence on their career choice and professional identity. Although students at the main campus are required to complete a rural clerkship, the 2 regional medical campuses have a sustained emphasis on rural practice.

Attitudes and values are particularly susceptible to influence from the context of training. ${ }^{27}$ The regional medical campuses provide a different kind of learning experience than the main campus, because they service smaller populations that are more geographically scattered and have less access to specialized care. Role models, mentors, role expectations, respect and collegiality, and scope of practice may all affect students' career decisions. We postulate that learners embedded within the context of the regional medical campuses are strongly influenced by the broad activities and relationships they encounter. ${ }^{28}$ They are engaged in a broad scope of rural and regional medical practice throughout their 4 years, learning by participating in local health services. They also have more opportunity to develop — and maintain — relationships with generalist clinicians who are more visible in the medical education community. As their competence grows, so does their professional identity, becoming more consistent with family and rural practice. ${ }^{29}$

\section{Limitations}

There are several limitations to be noted in this study. We included demographic variables known to predict rural family practice (e.g., sex, age at time of entry and rural background). 


\begin{tabular}{|c|c|c|c|c|}
\hline Characteristic & Rural practice & Urban practice & $p$ value & Effect size $^{*}$ \\
\hline \multicolumn{5}{|l|}{ Sex, no (\%) } \\
\hline Female $(n=187)$ & $22(11.8)$ & 165 (88.2) & \multirow[t]{2}{*}{0.4} & \multirow[t]{2}{*}{0.04} \\
\hline Male $(n=122)$ & $18(14.8)$ & $104(85.2)$ & & \\
\hline \multicolumn{5}{|l|}{ Rural background, no. (\%)† } \\
\hline Rural $(n=38)$ & $12(31.6)$ & $26(68.4)$ & \multirow[t]{2}{*}{$<0.001$} & \multirow[t]{2}{*}{0.22} \\
\hline Urban $(n=263)$ & $27(10.3)$ & $236(89.7)$ & & \\
\hline $\begin{array}{l}\text { Age at entry into UBC MD training, } \\
\text { mean } \pm \text { SD }\end{array}$ & $27.2 \pm 5.1$ & $25.4 \pm 4.0$ & 0.01 & 0.39 \\
\hline \multicolumn{5}{|l|}{ Campus, no. (\%) } \\
\hline Main campus $(n=211)$ & $14(6.6)$ & $197(93.4)$ & \multirow[t]{3}{*}{$<0.001$} & \multirow[t]{3}{*}{0.32} \\
\hline IMP-RMC $(n=42)$ & $7(16.7)$ & 35 (83.3) & & \\
\hline NMP-RMC $(n=56)$ & $19(33.9)$ & $37(66.1)$ & & \\
\hline \multicolumn{5}{|c|}{$\begin{array}{l}\text { Note: IMP-RMC = Island Medical Program regional medical campus, MD = medical degree, NMP-RMC = Northern Medical Campus } \\
\text { regional medical program, } \mathrm{SD}=\text { standard deviation, UBC = University of British Columbia. } \\
{ }^{\circ} \text { Cramér's } V \text { was calculated to determine effect size for sex, rural background and campus; Cohen's } d \text { was calculated to determine } \\
\text { effect size for age at entry into medical school. } \\
\text { †Data were missing for } 8 \text { students. }\end{array}$} \\
\hline
\end{tabular}

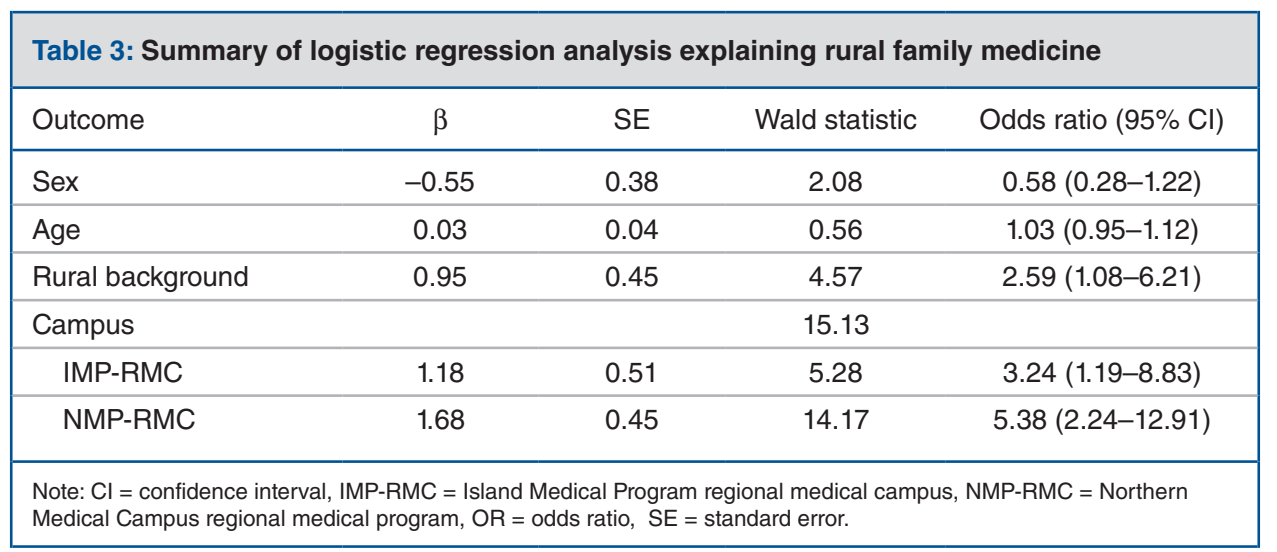

However, there are other variables that were not included because they were not available from our institutional database. Other predictors that should be explored in future research include being in a relationship, having a social orientation, wanting a varied scope of practice, ${ }^{18}$ planning to have a rural practice and planning to practise family medicine. ${ }^{19}$ The use of a dichotomous rural/urban variable did not allow us to interpret physicians' practice reach. Thus, we may have underestimated "rural practice" because the RST definition does not account for access to health care (e.g., physicians with an office in Prince George could serve patients from surrounding rural areas, but they would not be classified as practising rural family medicine). Our results represent a single point in time, and physicians in rural family practice may later change their location of practice. National databases currently do not fully capture physicians who take on sessional practice or who spend time providing locum services in rural areas before settling into long-term practice. Finally, we did not include location of post-MD training in this study. Future research could address many of these limitations using a prospective cohort study design, a larger sample size and multiple observation points. It will also be of interest to examine the impact of this regional medical campus model on the number of specialists choosing rural practice over time.

\section{Conclusion}

The evidence from this study suggests that a combined regional campus model in medical education matters. The full impact of this model will not be known for years to come; however, a decade after implementation, the outcomes suggest that the approach can make a positive contribution to addressing gaps in rural family practice and that regional campuses are an important part of the pipeline to family practice and rural recruitment. Their most important influence may 
be to provide students with experience in contexts of rural and family medicine and exposure to physician role models with fulfilling family practice careers.

\section{References}

1. Health at a glance: Europe 2014. Paris: OECD [Organisation for Economic Co-operation and Development] Publishing; 2014.

2. Increasing access to bealth workers in remote and rural areas through improved retention: global policy recommendations: World Health Organization; 2010.

3. Sibley LM, Weiner JP. An evaluation of access to health care services along the rural-urban continuum in Canada. BMC Health Serv Res 2011;11:20.

4. Access to a regular medical doctor. Ottawa: Statistics Canada; 2013. Cat no 82-625-X. Available: www.statcan.gc.ca/pub/82-625-x/2014001/article/14013 -eng.htm (accessed 2019 May 16).

5. A profile of physicians in Canada, 2017. Ottawa: Canadian Institute for Health Information; 2017. Available: www.cihi.ca/en/a-profile-of-physicians-in-canada -2017 (accessed 2019 May 13)

6. Population and dwelling count bighlights tables, 2016 census. Ottawa: Statistics Canada; 2016. Available: www12.statcan.gc.ca/census-recensement/2016/dp-pd/hlt-fst/ $\mathrm{pd}-\mathrm{pl} /$ Table.cfm? $\mathrm{Lang}=\mathrm{Eng} \& \mathrm{~T}=703 \& \mathrm{~S}=87 \& \mathrm{O}=\mathrm{A}$ (accessed 2019 May 16).

7. Cheifetz CE, McOwen KS, Gagne P, et al. Regional medical campuses: a new classification system. Acad Med 2014;89:1140-3.

8. Physicians in Canada, 2015: summary report. Ottawa: Canadian Institute for Health Information; 2016.

9. Snadden D, Bates J. Expanding undergraduate medical education in British Columbia: a distributed campus model. CMA7 2005;173:589-90.

10. Mapping undergraduate distributed medical education in Canada, 2010. Ottawa: Association of Faculties of Medicine in Canada; 2010.

11. Viscomi M, Larkins S, Sen Gupta T. Recruitment and retention of general practitioners in rural Canada and Australia: a review of the literature. Can 7 Rural Med 2013;18:13-23.

12. Bosco C, Oandasan I. Review of family medicine within rural and remote Canada: education, practice and policy. Mississauga (ON): College of Family Physicians of Canada; 2016.

13. Grobler L, Marais BJ, Mabunda S. Interventions for increasing the proportion of health professionals practising in rural and other underserved areas. Cocbrane Database Syst Rev 2015;(6):CD005314.

14. Focus on geography series, 2016 census. Ottawa: Statistics Canada; 2017. Cat no 98-404-X2016001. Available: www12.statcan.gc.ca/census-recensement/2016/ as-sa/fogs-spg/Facts-pr-eng.cfm?Lang=eng\&GK=PR\&GC=59\&TOPIC=1 (accessed 2019 May 16).

15. Bates J, Frinton V, Voaklander D. A new evaluation tool for admissions. Med Educ 2005;39:1146.

16. du Plessis V, Beshiri R, Bollman RD, et al. Definitions of "rural." Agricultural and rural working paper series working paper no. 61. Ottawa: Statistics Canada; 2002. Cat no 21-601-MIE. Available: www150.statcan.gc.ca/n1/ pub/21-601-m/2002061/4224867-eng.pdf (accessed 2019 May 12).

17. Geographic attribute file, reference guide: census year 2011. Ottawa: Statistics Canada; 2011. Cat no 92-151-X. Available: www150.statcan.gc.ca/n1/en/ pub/92-151-g/92-151-g2011001-eng.pdf?st=iMTu5iyc (accessed 2019 May 16).

18. Mitra G, Gowans M, Wright B, et al. Predictors of rural family medicine practice in Canada. Can Fam Physician 2018;64:588-96.

19. Rabinowitz HK, Diamond JJ, Markham FW, et al. The relationship between entering medical students' backgrounds and career plans and their rural practice outcomes three decades later. Acad Med 2012;87:493-7.
20. Laven G, Wilkinson D. Rural doctors and rural backgrounds: How strong is the evidence? A systematic review. Aust 7 Rural Health 2003;11:277-84.

21. Strasser R. Social accountability and the supply of physicians for remote rural Canada. CMA7 2015;187:791-2.

22. Woolley T, Sen Gupta T, Murray R. James Cook University's decentralised medical training model: an important part of the rural workforce pipeline in northern Australia. Rural Remote Health 2016;16:3611

23. Kwan MMS, Kondalsamy-Chennakesavan S, Ranmuthugala G, et al. The rural pipeline to longer-term rural practice: general practitioners and specialists. PLoS One 2017;12:e180394.

24. Hogenbirk JC, Timony PE, French MG, et al. Milestones on the social accountability journey: family medicine practice locations of Northern Ontario School of Medicine graduates. Can Fam Physician 2016;62:e138-45.

25. Farmer J, Kenny A, McKinstry C, et al. A scoping review of the association between rural medical education and rural practice location. Hum Resour Health 2015;13:27.

26. Mathews M, Ryan D, Samarasena A. Work locations in 2014 of medical graduates of Memorial University of Newfoundland: a cross-sectional study. CMAJ Open 2015;3:E217-22.

27. Bates J, Ellaway RH. Mapping the dark matter of context: a conceptual scoping review. Med Educ 2016;50:807-16.

28. Lave J, Wenger E. Situated learning: legitimate peripheral participation. Cambridge (UK): Cambridge University Press; 1991.

29. Wenger E. Communities of practice and social learning systems. Organization 2000;7:225-46.

Affiliations: School of Population and Public Health (Lovato), Evaluation Studies Unit (Hsu), Department of Family Practice (Bates, Snadden), Centre for Health Education Scholarship (Bates, Casiro, Towle), Department of Pediatrics (Casiro) and Department of Medicine (Towle), Faculty of Medicine, University of British Columbia, Vancouver, BC; Department of Family Practice (Snadden), Northern Medical Program, Prince George, BC

Contributors: Chris Lovato conceived the study and all of the authors assisted in the conceptual design and in the interpretation of the data. Helen Hsu performed the data analyses. Chris Lovato, Helen Hsu, David Snadden and Joanna Bates drafted the manuscript. All of the authors contributed to revising the manuscript critically for important intellectual content, gave approval of the final version to be published and agreed to be accountable for all aspects of the work.

Acknowledgements: The authors wish to thank Kevin Eva for his comments on an earlier version of this paper, Shayna Rusticus for her statistical consultation and Marliese Dawson for her editorial support.

Disclaimer: This study was conducted using secondary data from the Evaluation Studies Unit, Faculty of Medicine, University of British Columbia. The university had no role in the design, study implementation, analysis or interpretation of the data; review or approval of the manuscript; and decision to submit for publication.

Supplemental information: For reviewer comments and the original submission of this manuscript, please see www.cmajopen.ca/content $/ 7 / 2$ / E415/suppl/DC1. 